\title{
Frictionless segmented mechanics for controlled space closure
}

\author{
Ildeu Andrade Jr ${ }^{1}$
}

DOI: $h t t p: / / d x . d o i . o r g / 10.1590 / 2176-9451.22 .1 .098-109 . b b o$

\begin{abstract}
Extraction spaces may be needed to achieve specific orthodontic goals of positioning the dentition in harmony with the craniofacial complex. However, the fundamental reality that determines the occlusion final position is the control exerted by the orthodontist while closing the extraction spaces. A specific treatment objective may require the posterior teeth to remain in a constant position anteroposteriorly as well as vertically, while the anterior teeth occupy the entire extraction site. Another treatment objective may require the opposite, or any number of intentional alternatives of extraction site closure. The present case report describes a simple controlled segmented mechanic system that permitted definable and predictable force systems to be applied and allowed to predict the treatment outcome with confidence. This case was presented to the Brazilian Board of Orthodontics and Dentofacial Orthopedics (BBO) in partial fulfillment of the requirements for Diplomate certification.
\end{abstract}

Keywords: Angle Class II malocclusion. Dental extraction. Corrective orthodontics.

\begin{abstract}
Os espaços gerados pelas extrações de pré-molares podem ser necessários para que objetivos ortodônticos específicos sejam alcançados dentro do complexo craniofacial. No entanto, a realidade fundamental que determina a posição final da oclusão é o controle biomecânico exercido pelo ortodontista no fechamento dos espaços das extrações. Um objetivo específico do tratamento pode exigir que os dentes posteriores permaneçam estáveis em uma posição sagital e vertical, enquanto os dentes anteriores são retraídos e ocupam todo o espaço da extração. Outro objetivo de tratamento pode exigir o inverso, ou quaisquer alternativas intencionais de fechamento de espaços de extração. O presente relato de caso descreve um sistema simples de mecânica segmentada que permite, de maneira controlada, que sistemas com forças definidas e previsíveis sejam aplicados, permitindo também predizer o resultado do tratamento com segurança. Esse caso foi apresentado ao Board Brasileiro de Ortodontia e Ortopedia Facial (BBO), em cumprimento parcial dos requisitos para certificação.
\end{abstract}

Palavras-chave: Má oclusão Classe II de Angle. Extração dentária. Ortodontia corretiva.

\section{INTRODUCTION}

This patient was a healthy 31 -year-old woman with a chief complaint of "protruded teeth affecting my smile". Her medical history showed no contraindication to orthodontic treatment. There was no history of dental trauma or oral habits. The patient had good

${ }^{1}$ Adjunct Professor, Pontifícia Universidade Católica, Minas.

» Patients displayed in this article previously approved the use of their facial and intraoral photographs.

Submitted: December 06, 2016 - Revised and accepted: December 16, 2016 oral hygiene. Regarding function, the patient presented lateral disocclusion through molar guidance on the right side. Mouth opening and closure movements were performed without deviation. No signs or symptoms of temporomandibular dysfunction were noted.

How to cite this article: Andrade Jr I. Frictionless segmented mechanics for controlled space closure. Dental Press J Orthod. 2017 Jan-Feb;22(1):98-109. DOI: http://dx.doi.org/10.1590/2176-9451.22.1.098-109.bbo

" The author reports no commercial, proprietary or financial interest in the products or companies described in this article.

Contact address: Ildeu Andrade Jr. Rua Padre Rolim, 815, conj. 406 - Santa Efigênia CEP: 30.130-090 - Belo Horizonte/MG Brasil E-mail: ildeuandrade@pucminas.br 


\section{DIAGNOSIS}

The extraoral examination disclosed an asymmetrical face, a slightly convex profile with a deep mentolabial sulcus and an excessive incisor display at rest. The lips were incompetent and the patient could not close them without causing tension in the orbicularis oris muscles. Moreover, the lower lip was procumbent, $4.5 \mathrm{~mm}$ ahead of the Steiner's S-line (Table 1). Intraorally, she presented a bilateral endto-end Class II, with a severe bimaxillary protrusion, an overjet of $5 \mathrm{~mm}$ and a pronounced curve of Spee (Fig 1). The Bolton analysis was equal to $75.3 \%$ in the anterior teeth and equal to $87.1 \%$ of total (Fig 2). Both arches were constricted in the posterior region, which contributed to the creation of the "black corridors".
The panoramic radiographs (Fig 3) shows that all teeth were present except the third molars. No changes were noted in the bone or the periodontal and periapical aspects. The initial cephalogram (Fig 4) and its tracing reveals an ANB angle of $3.5^{\circ}$ and an Angle of Convexity equal to $2^{\circ}$. The FMA, Y-axis and $\mathrm{SN}-\mathrm{GoGn}$ were equal to $18^{\circ}, 52^{\circ}$ and $30^{\circ}$, respectively. The maxillary and mandibular incisors were significantly flared, with a maxillary central incisor to SN angle of $117^{\circ}, 1 . \mathrm{NA}$ of $32^{\circ}$; mandibular central incisor to MP angle of $105^{\circ}$, and $1 . \mathrm{NB}$ of $34^{\circ}$. The maxillary and mandibular incisors were also prominent relative to its supporting bone $(1-\mathrm{NA}=10 \mathrm{~mm} ; 1-\mathrm{NB}=10 \mathrm{~mm})($ Fig 4, Table 1$)$.
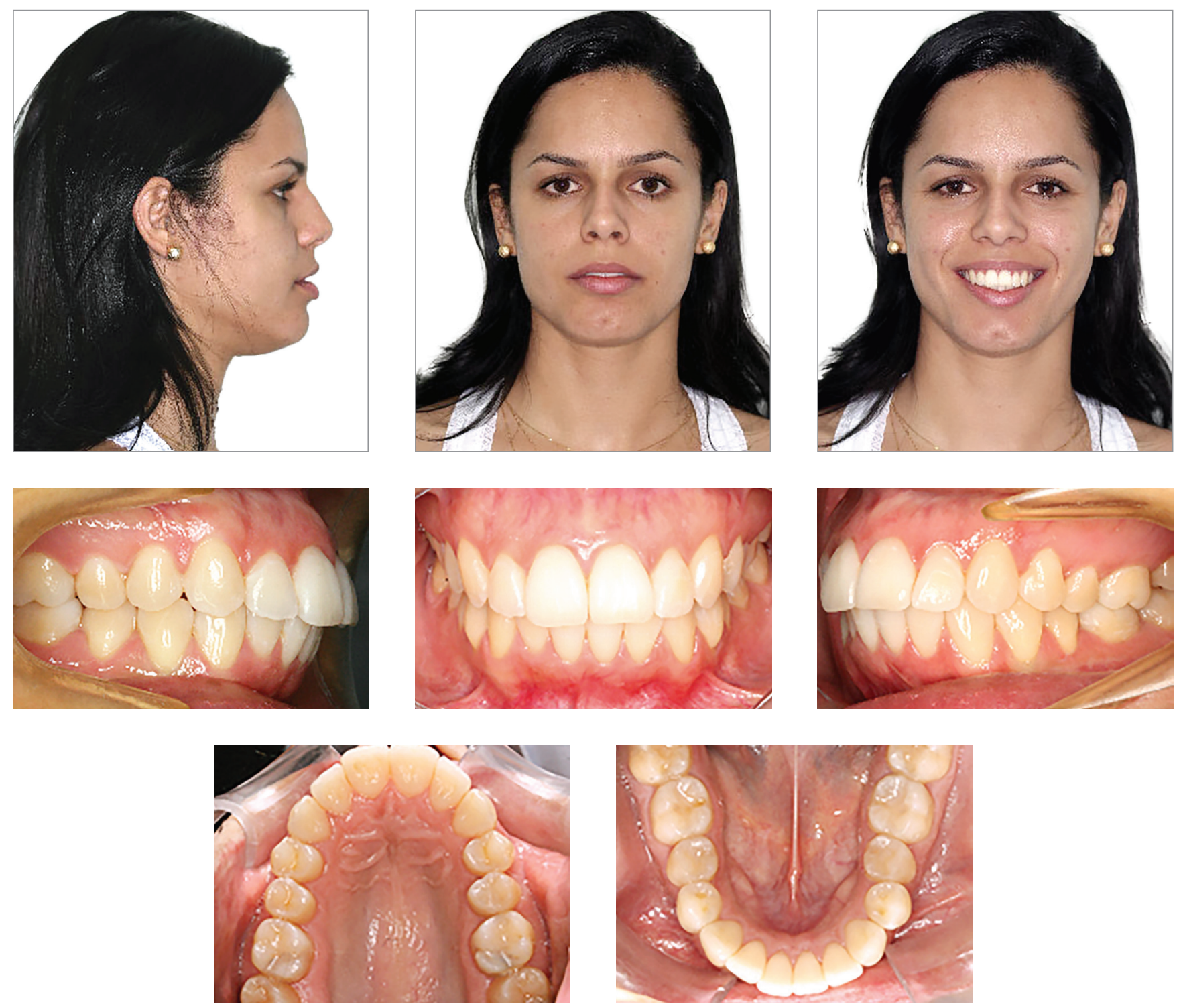

Figure 1 - Initial facial and intraoral photographs 

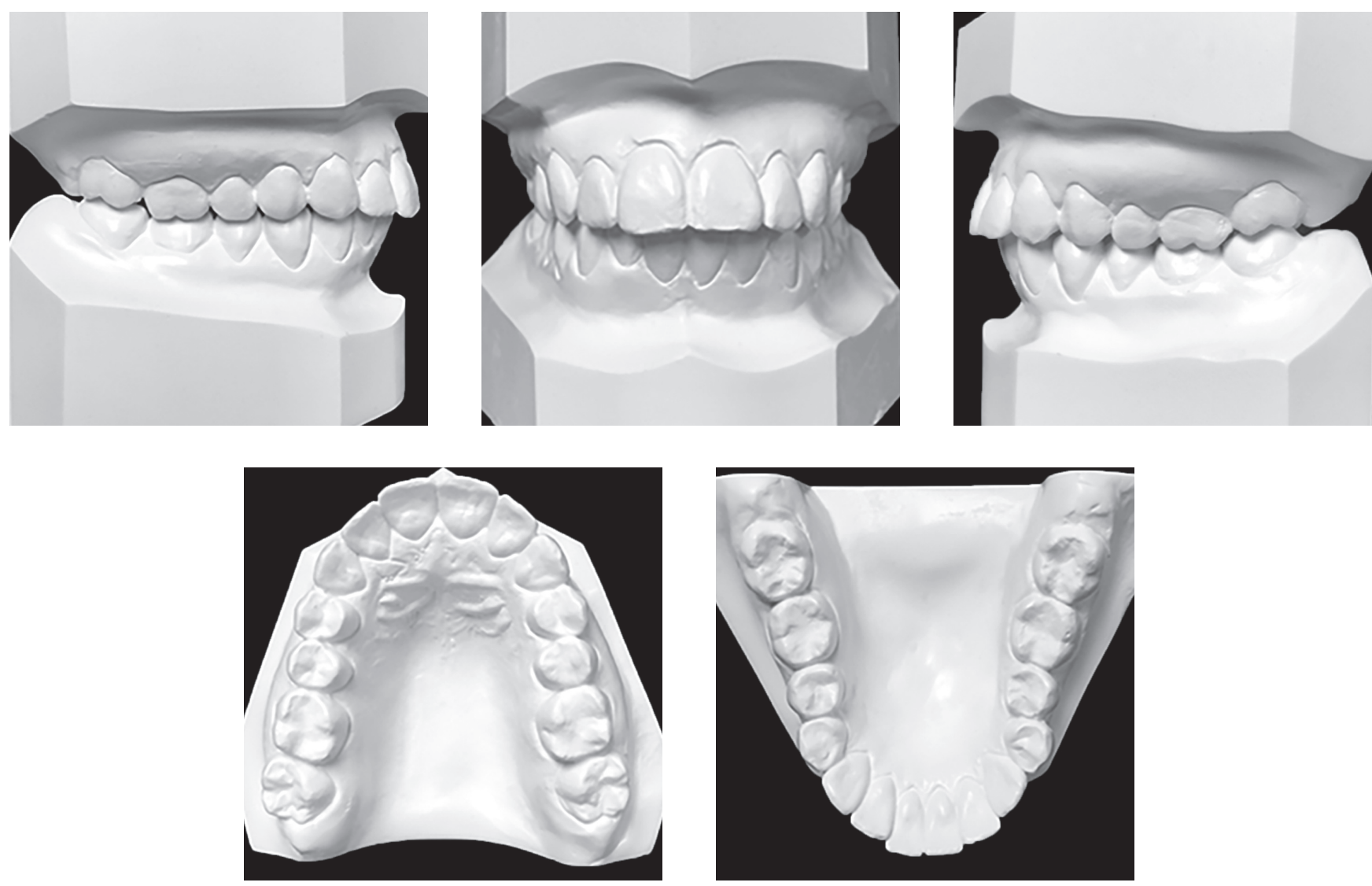

Figure 2 - Initial dental casts.

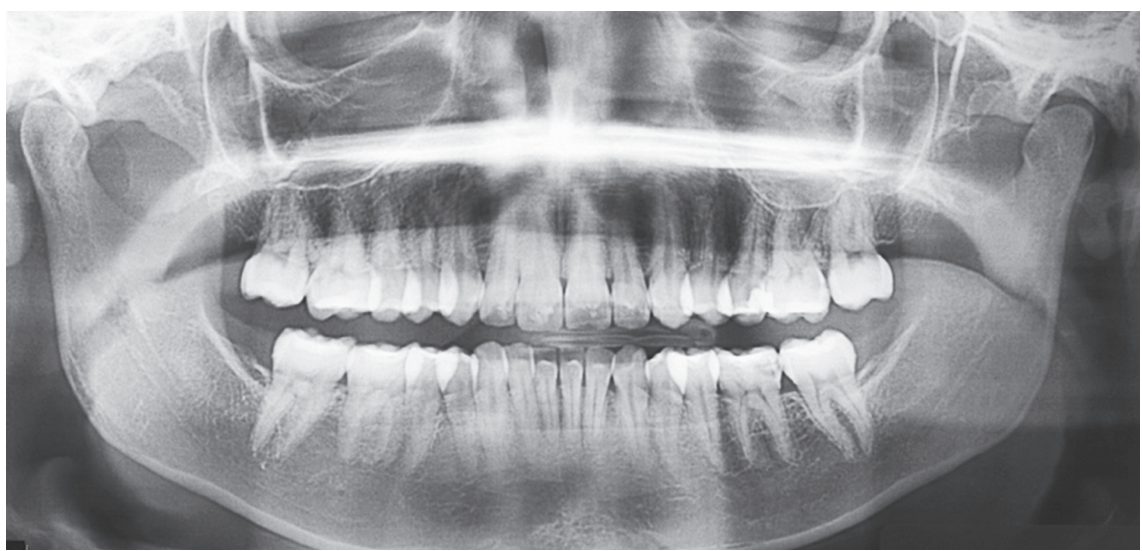

Figure 3 - Initial panoramic radiograph 


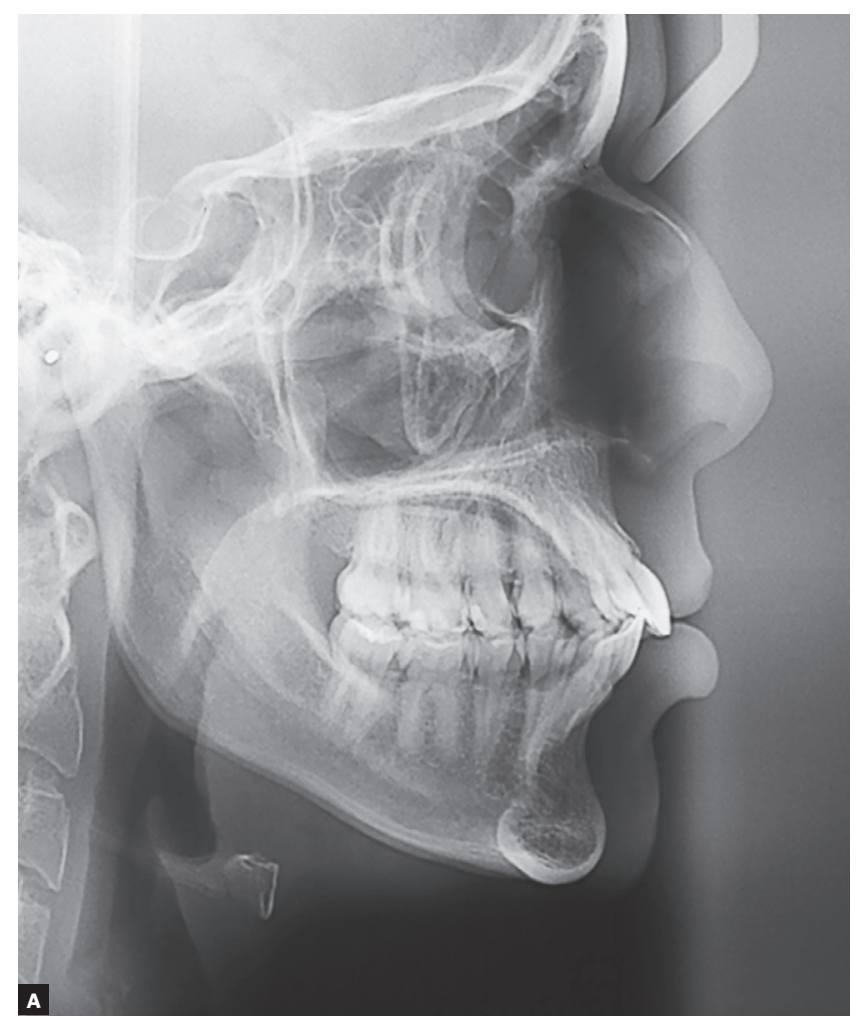

Figure 4 - Initial cephalogram (A) and cephalometric tracing (B).

\section{TREATMENT PLAN}

The treatment objectives were to: (1) reduce the excessive protrusion of both dental arches; (2) obtain normal canine and incisal guidance; (3) correct lip incompetence and lip strain on closure; (4) correct the Class II dental relationship; (5) level the curve of Spee; (6) achieve optimal overjet and overbite, and (7) improve the facial balance.

Based on these objectives, two treatment options were proposed, both requiring the extraction of all first premolars. The first alternative was to perform an en-masse retraction by using TADs. The pros and cons of absolute anchorage were explained. The second was a two-step space closure (beginning with canine retraction and followed by incisor retraction) with Frictionless controlled segmented mechanics and anchorage control without TADs. The patient refused any surgical treatment other than the extraction itself and requested the second option.

\section{TREATMENT PROGRESS}

A transpalatal bar and a lower lingual arch were placed for anchorage considerations, such as molar

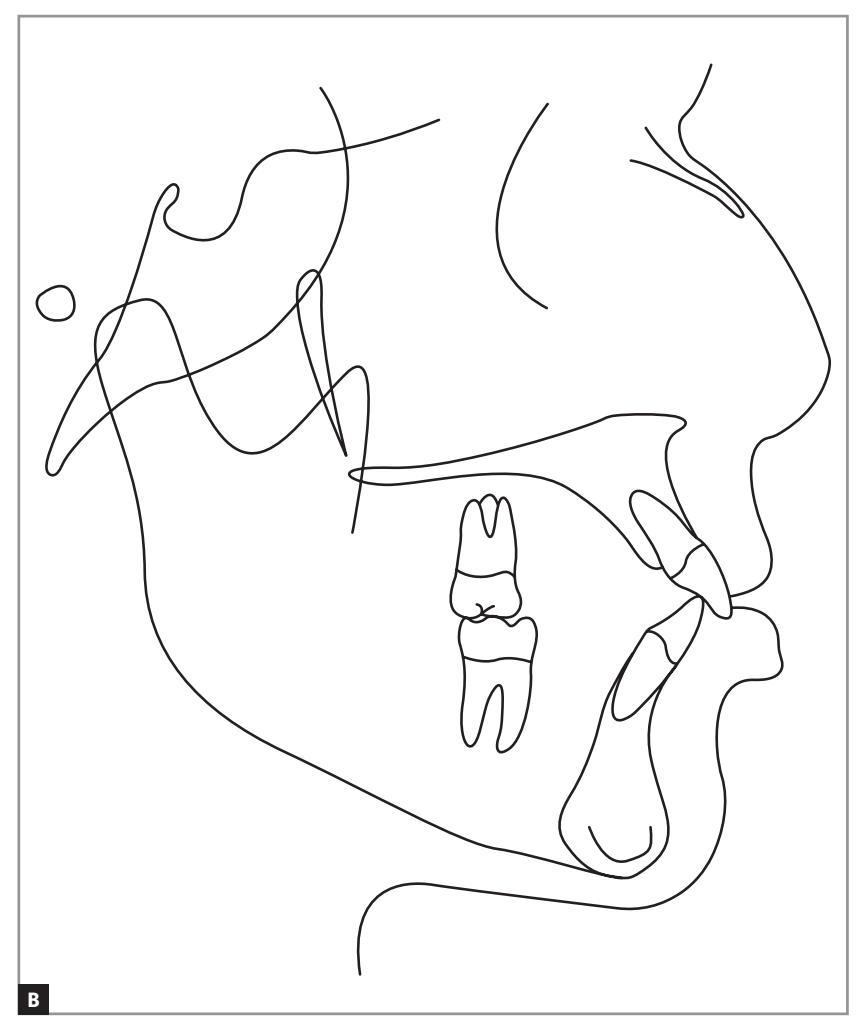

rotations and undesirable transverse changes, and the maxillary and mandibular first premolars were extracted two weeks after these appliance installation (Fig 5). Standard edgewise brackets and tubes were passively bonded to the maxillary and mandibular canines, second premolars and second molars (0.022-in American Orthodontics, Sheboygan, WI, EUA). The maxillary and mandibular incisors were also bonded for alignment and levelling. The distalization of the canines in both arches was initiated one week after extraction with segmented arch mechanics, using a Ricketts cuspid retractor made by a 0.016 x 0.016 -in Elgiloy (Rocky Mountain, Denver, CO, EUA), up to closure of $2 / 3$ of the spaces (Fig 5). Seven months later, the maxillary and mandibular incisors were than retracted simultaneously with closed $12-\mathrm{mm}$ length (150 g) NiTi closed coil springs (G\&H Orthodontics, Franklin, IN, EUA) adapted to two power arms on each quadrant (Fig 6A). The posterior power arms were located in the distal part of the auxiliary tubes of the first molars. The anterior ones were part of a wire passing through the slots of the incisors, creating an incisor segment. The posterior and anterior power 
arms were constructed to be as close as possible to the center of rotation of the molar and incisor segments, respectively (Fig 6). As the objective was to close the extraction spaces and at the same time upright the maxillary and mandibular incisors, the height of the power arms were adjusted throughout the treatment as needed (eg. shortening of the anterior power arms provides more lingual/palatal crown torque).

Once the incisors were fully retracted (6 months), the patient was debonded and them rebonded for final alignment and levelling. Once the arches were aligned and leveled, continuous $0.017 \times 0.025$-in stainless steel (SS) arch wires were inserted in both arches and the patient was instructed to wear $3 / 8$ ounces Class II elastics. Three months later, $0.019 \times 0.025$-in SS wires were placed for torquing control. Root paralleling and vertical elastics were used to detail and settle down the occlusion.

The appliances were removed after 24 months of treatment, when a maxillary wraparound and a mandibular bonded premolar-to-premolar fixed retainer were installed on the patient.
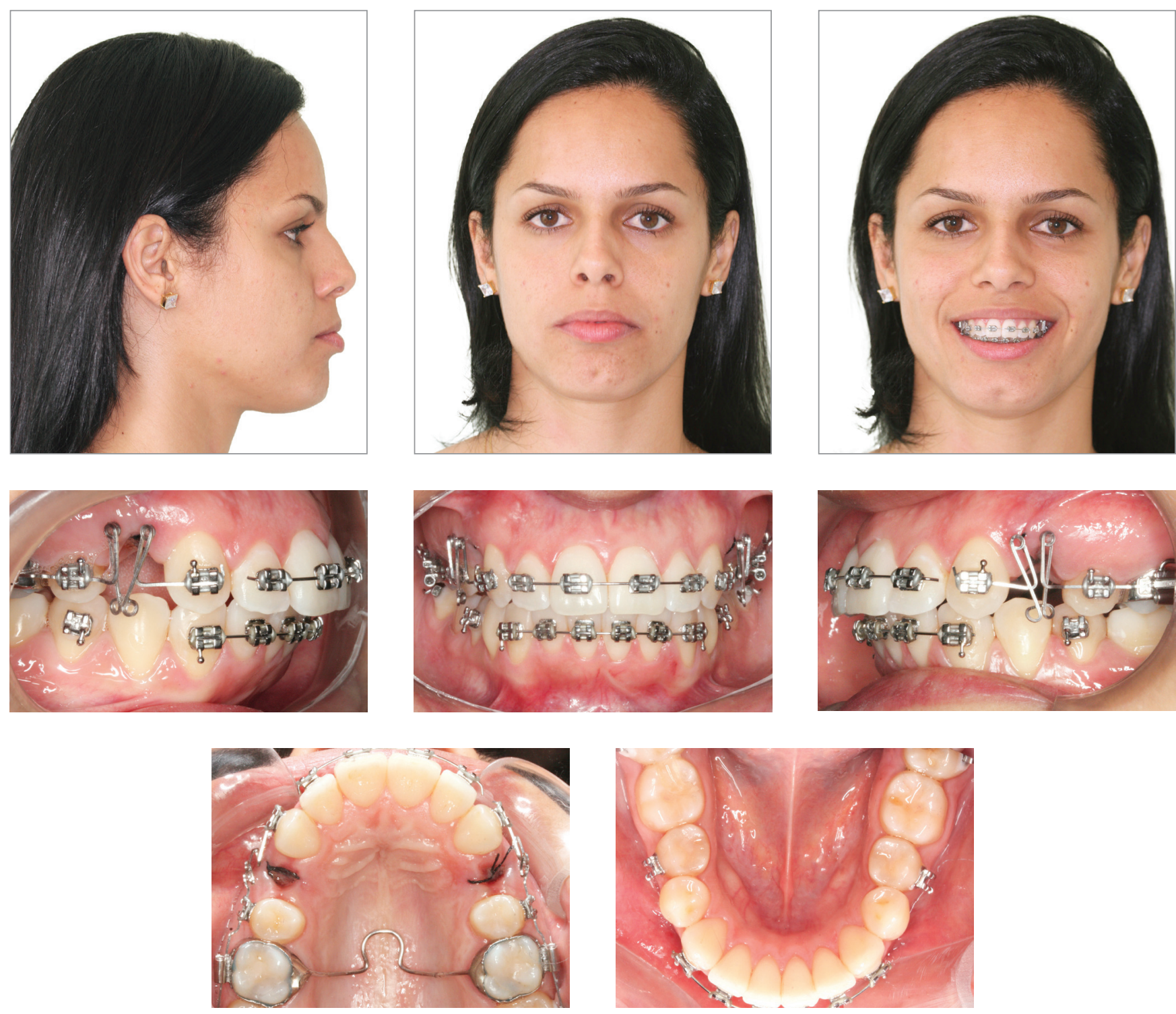

Figure 5 - Progress records (canines' distalization) 

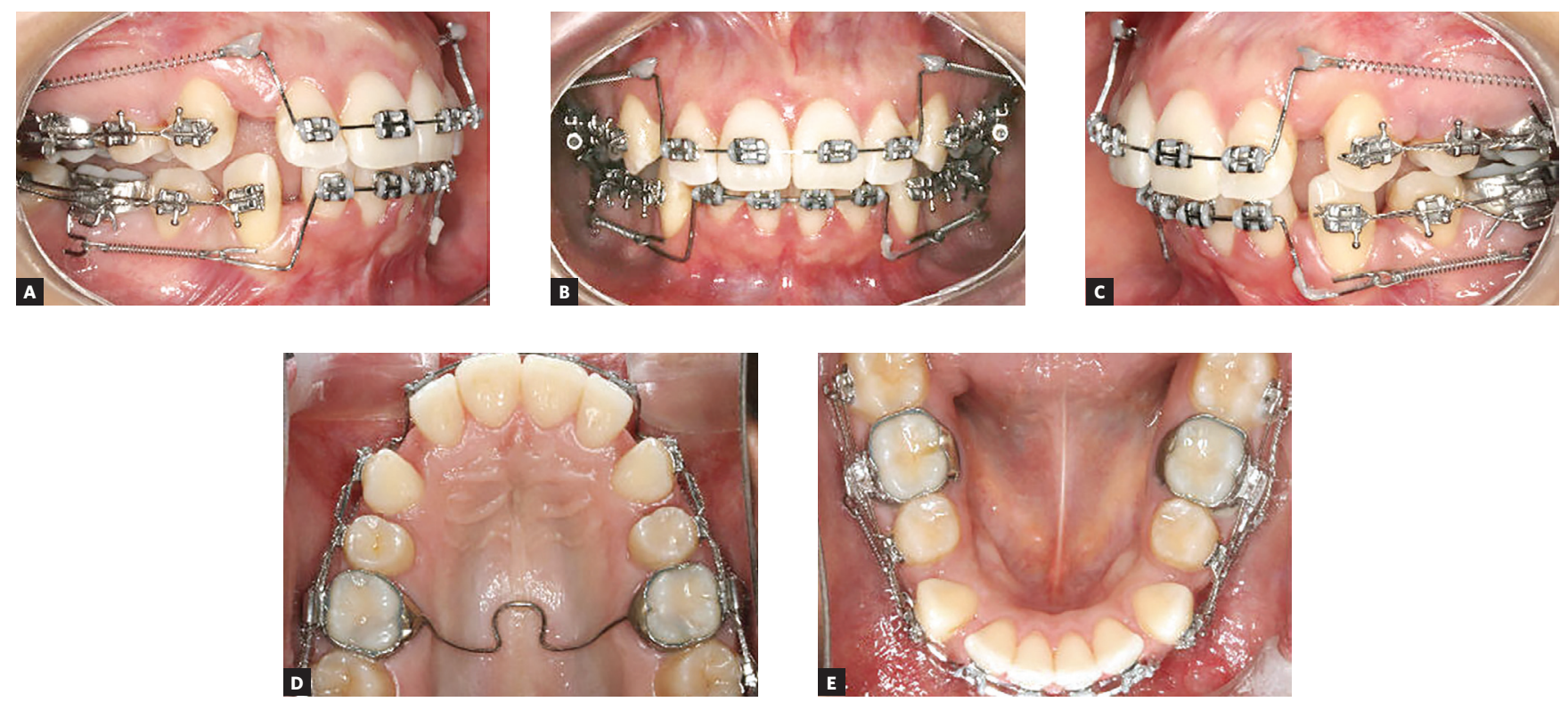

Figure 6 - Progress records (incisors' retraction)

\section{RESULTS}

The posttreatment facial and intraoral photographs (Fig 7) illustrate the improvement in the patient's profile. The profile line to nose relationship improved and no mentalis strain was noted. The lips were competent at rest and the upper lip to S-plane changed from 1 to $-2.5 \mathrm{~mm}$; the lower lip to S-plane changed from 4.5 to $0 \mathrm{~mm}$. Frontal analysis revealed a balanced face, with proportional facial thirds and an esthetically pleasant smile.

The posttreatment dental casts (Fig 8) and intraoral photos (Fig 7) show an Angle Class I occlusion with normal overjet, overbite, and canine and incisal guidance. There was a slight increase in the mandibular arch transverse dimension, as needed.

The posttreatment panoramic radiograph (Fig 9) shows that all spaces were closed without alveolar bone loss and root resorption after treatment. The posttreatment cephalometric radiograph and its tracing (Fig 10) illustrate the changes achieved with treatment. As planned, the maxillary incisors were uprighted $17^{\circ}$ and $7 \mathrm{~mm}$ over the basal bone (to a final 1.NA of $14.5^{\circ}$ and $1-\mathrm{NA}$ of $3 \mathrm{~mm}$ ). Mandibular incisors were retracted $16.5^{\circ}$ and $6 \mathrm{~mm}$ from the mandibular plane (to a final IMPA angle of $88.5^{\circ}$ and $1-\mathrm{NB}$ of $\left.4 \mathrm{~mm}\right)$. The interin-

cisal angle was significantly increased $\left(32^{\circ}\right)$. The FMA angle increased $2^{\circ}$ (from $18^{\circ}$ to $20^{\circ}$ ) and the SN-GoGn reduced $1^{\circ}\left(\right.$ from $30^{\circ}$ to $29^{\circ}$ ) (Table 1$)$.

The cephalometric tracings confirmed that the maxillary and mandibular incisors were significantly uprighted and the lower lip soft tissue protrusion was reduced (Figs 4 and 10). Cephalometric tracings superimposition also revealed no extrusion in the maxillary and mandibular molars. As predicted and desired, the sagittal position of the maxillary molars remained almost unchanged, with minimal anchorage loss; and the mandibular ones slightly came forward to achieve a Class I relationship.

The case was retained by means of a maxillary wraparound retainer and a bonded premolar-to-premolar fixed retainer in the mandibular arch. The patient was instructed to only remove the retainer during periods of eating and toothbrushing. The appointments were set in 2 to 3 months intervals in the first year and 6 months intervals in the second year.

Treatment objectives were achieved with excellent esthetic and functional results. The patient became very happy with the results of her treatment, which was accomplished in 24 months. 

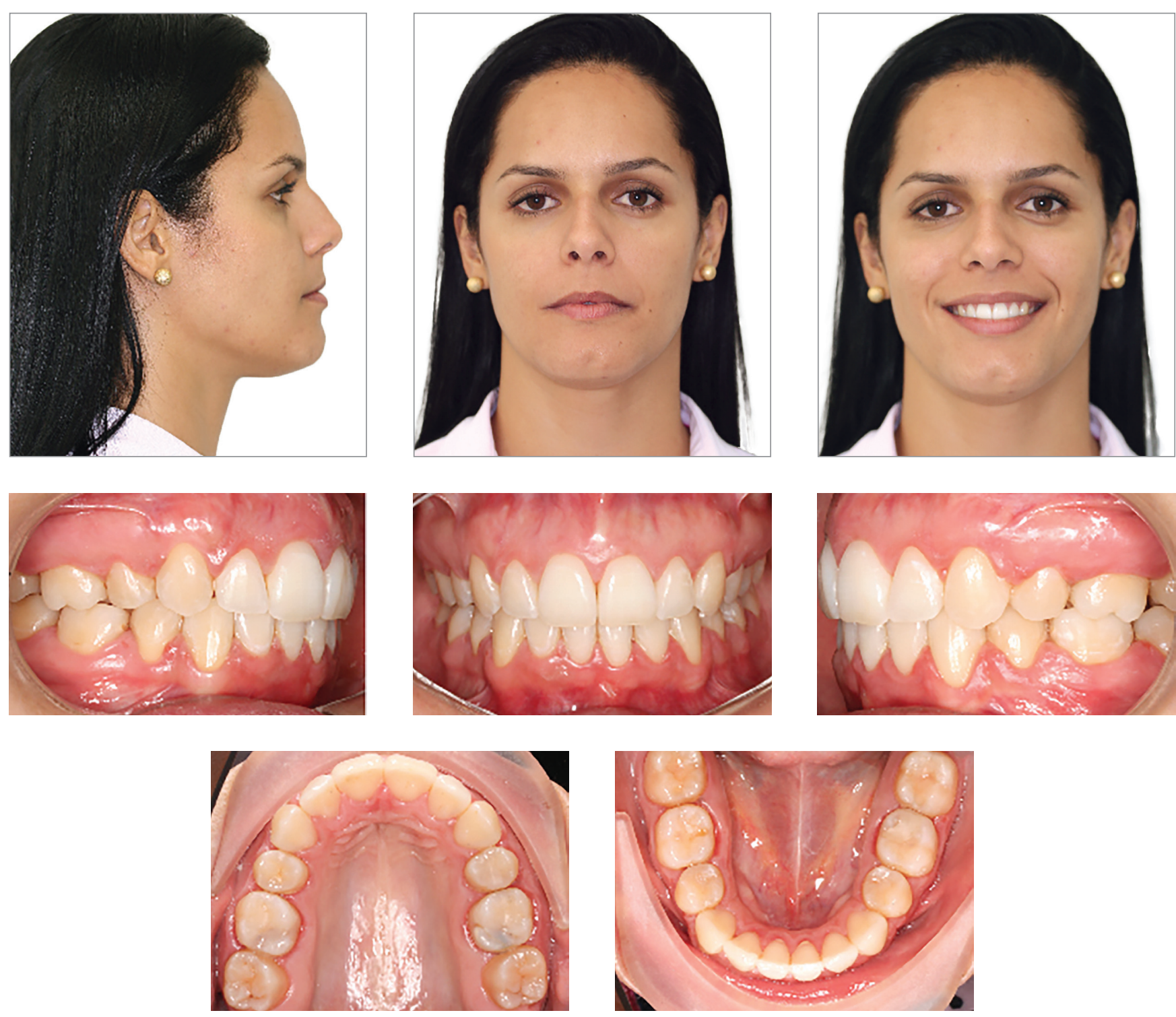

Figure 7 - Final facial and intraoral photographs. 

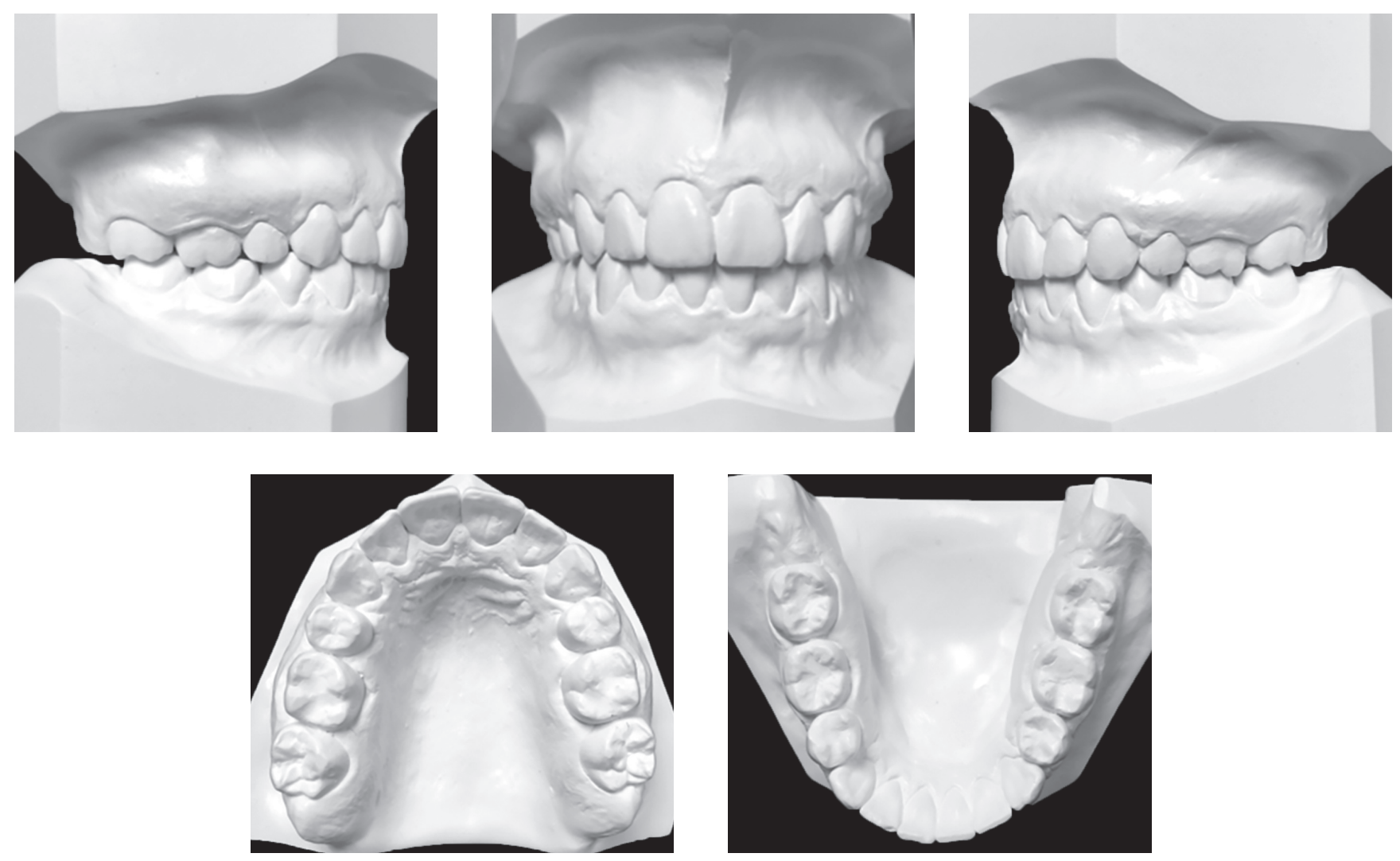

Figure 8 - Final dental casts.

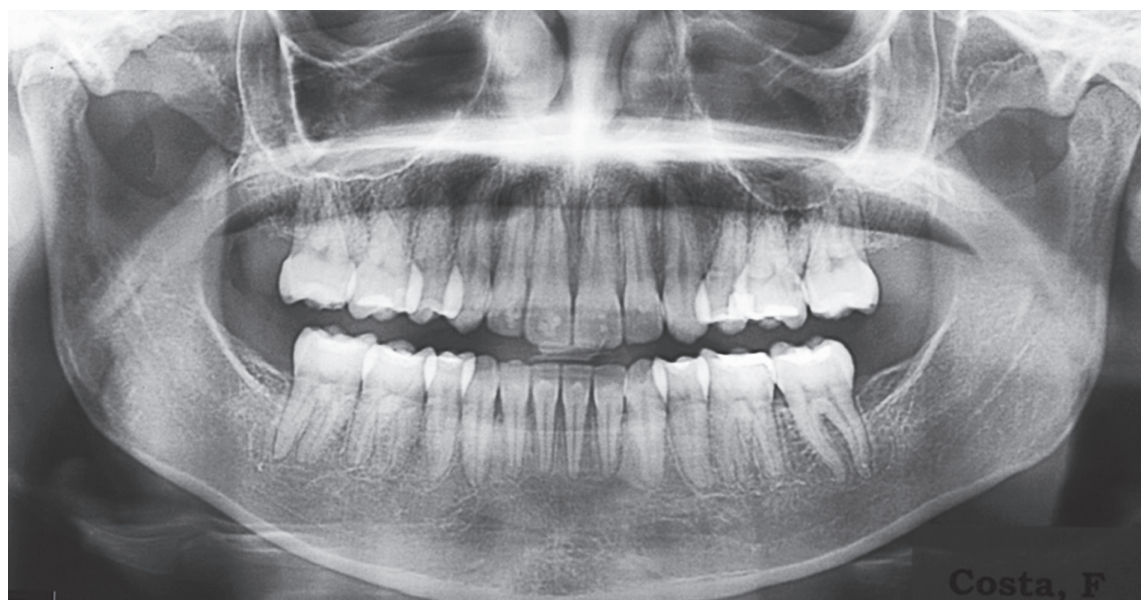

Figure 9 - Final panoramic radiograph. 

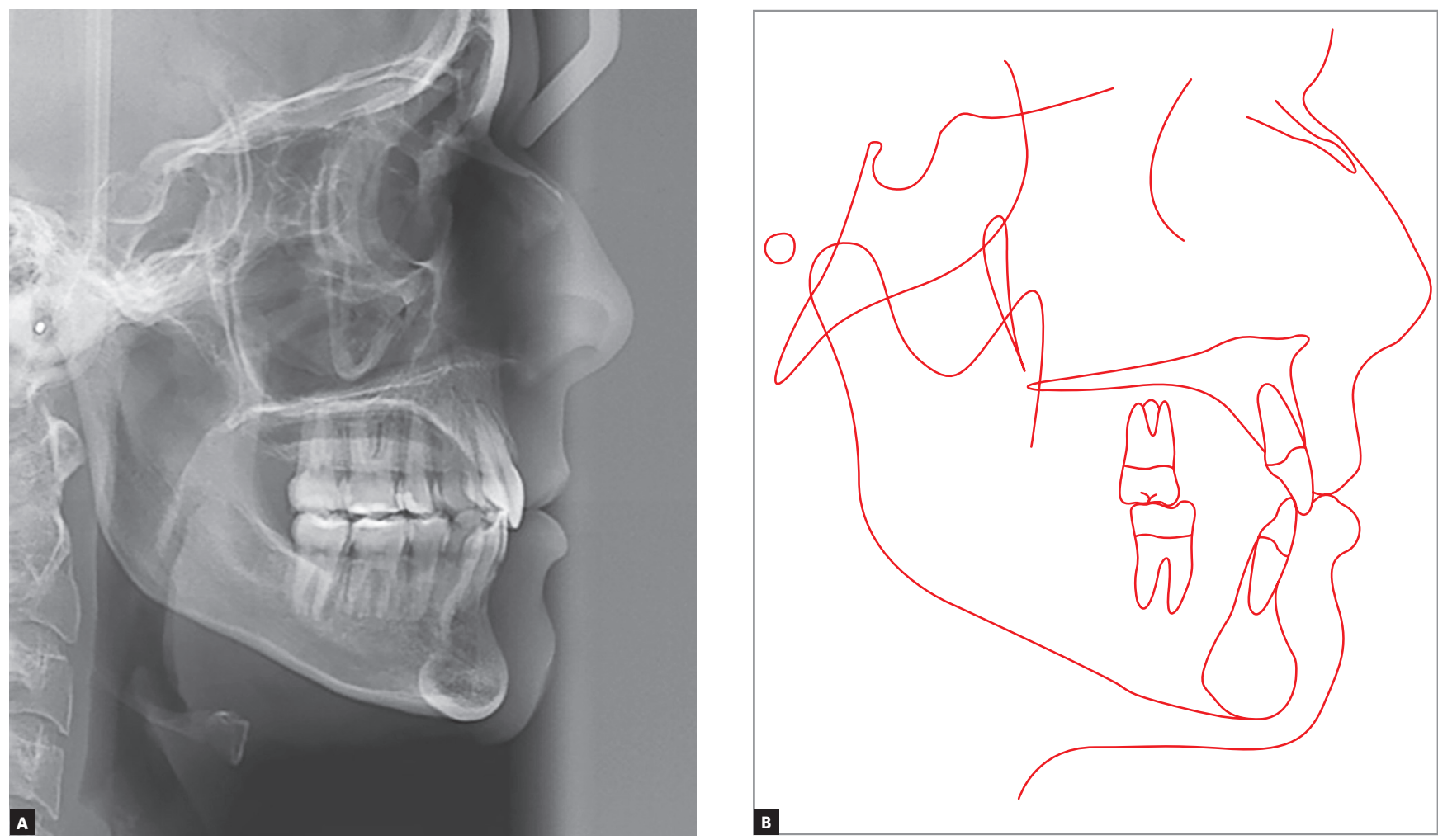

Figure 10 - Final profile cephalometric radiograph (A) and cephalometric tracing (B).
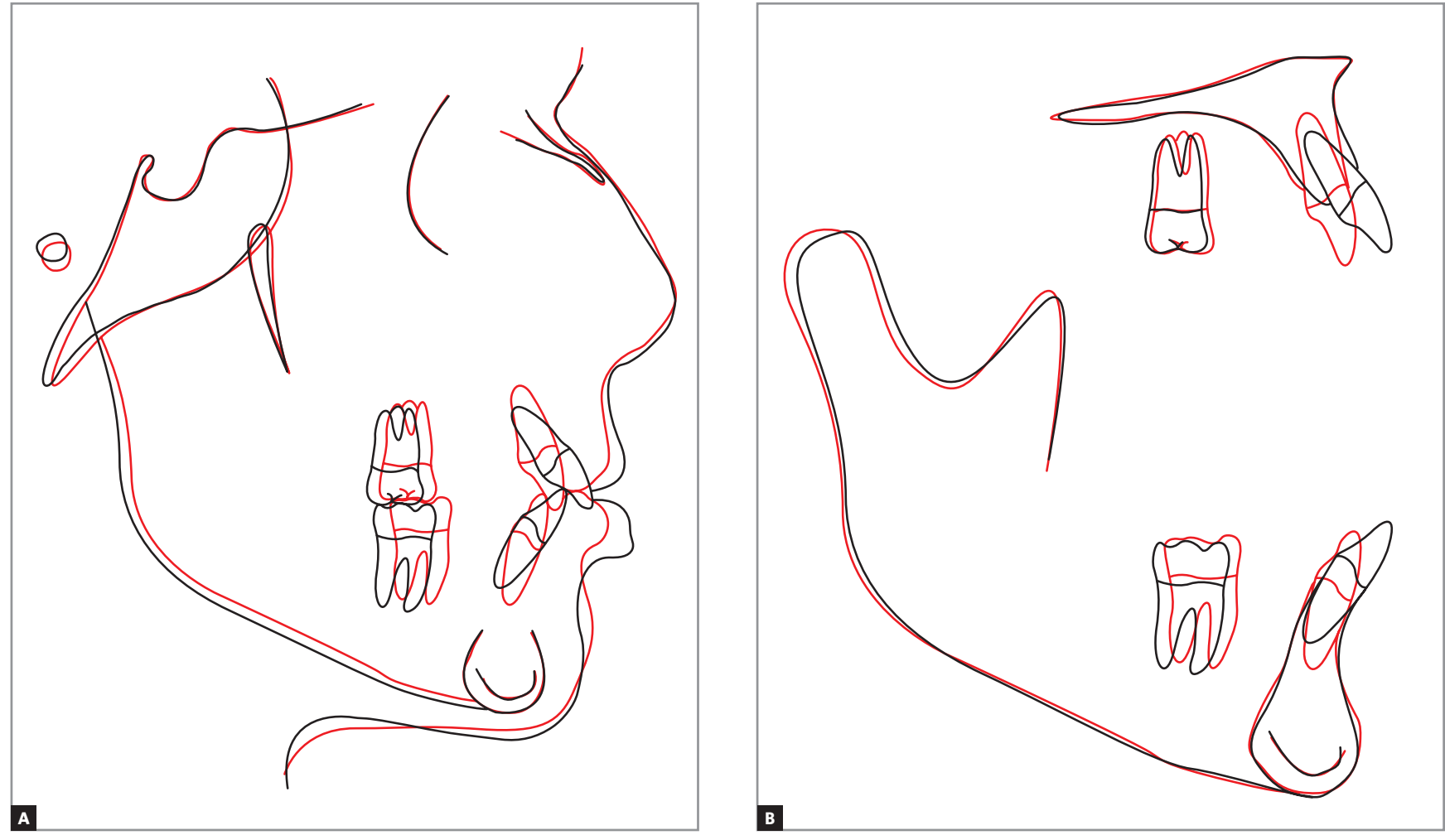

Figure 11 - Total (A) and partial (B) superimpositions of initial (black) and final (red) cephalometric tracings. 
Table 1 - Cephalometric measurements: initial (A) and final (B)

\begin{tabular}{|c|c|c|c|c|c|c|}
\hline & Measurements & & Normal & A & B & A/B Diff. \\
\hline \multirow{9}{*}{$\begin{array}{l}\text { Skeletal } \\
\text { pattern }\end{array}$} & SNA & (Steiner) & $82^{\circ}$ & $83.5^{\circ}$ & $84^{\circ}$ & 0.5 \\
\hline & SNB & (Steiner) & $80^{\circ}$ & $80^{\circ}$ & $81^{\circ}$ & 1 \\
\hline & ANB & (Steiner) & $2^{\circ}$ & $3.5^{\circ}$ & $3^{\circ}$ & 0.5 \\
\hline & Wits & (Jacobson) & $\begin{array}{l}\text { o } 0 \pm 2 \mathrm{~mm} \\
\text { o } 1 \pm 2 \mathrm{~mm}\end{array}$ & $4 \mathrm{~mm}$ & $1 \mathrm{~mm}$ & 3 \\
\hline & Angle of convexity & (Downs) & $0^{\circ}$ & $2^{\circ}$ & $3^{\circ}$ & 1 \\
\hline & $Y$-axis & (Downs) & $59^{\circ}$ & $52^{\circ}$ & $53^{\circ}$ & 1 \\
\hline & Facial angle & (Downs) & $87^{\circ}$ & $95^{\circ}$ & $94.5^{\circ}$ & 0.5 \\
\hline & SN-GoGn & (Steiner) & $32^{\circ}$ & $30^{\circ}$ & $29^{\circ}$ & 1 \\
\hline & FMA & (Tweed) & $25^{\circ}$ & $18^{\circ}$ & $20^{\circ}$ & 2 \\
\hline \multirow{7}{*}{$\begin{array}{c}\text { Dental } \\
\text { pattern }\end{array}$} & IMPA & (Tweed) & $90^{\circ}$ & $105^{\circ}$ & $88.5^{\circ}$ & 16.5 \\
\hline & 1 .NA (degrees) & (Steiner) & $22^{\circ}$ & $31.5^{\circ}$ & $14.5^{\circ}$ & 17 \\
\hline & $1-\mathrm{NA}(\mathrm{mm})$ & (Steiner) & $4 \mathrm{~mm}$ & $10 \mathrm{~mm}$ & $3 \mathrm{~mm}$ & 7 \\
\hline & $\overline{1} . N B$ (degrees) & (Steiner) & $25^{\circ}$ & $34^{\circ}$ & $20^{\circ}$ & 14 \\
\hline & $\overline{1}-\mathrm{NB}(\mathrm{mm})$ & (Steiner) & $4 \mathrm{~mm}$ & $10 \mathrm{~mm}$ & $4 \mathrm{~mm}$ & 6 \\
\hline & $\frac{1}{1}$ - Interincisal angle & (Downs) & $130^{\circ}$ & $110^{\circ}$ & $142^{\circ}$ & 32 \\
\hline & $\overline{1}-A P O$ & (Ricketts) & $1 \mathrm{~mm}$ & $11 \mathrm{~mm}$ & $4 \mathrm{~mm}$ & 7 \\
\hline \multirow{2}{*}{ Profile } & Upper lip - S-line & (Steiner) & $0 \mathrm{~mm}$ & $1 \mathrm{~mm}$ & -2.5 & 3.5 \\
\hline & Lower lip - S-line & (Steiner) & $0 \mathrm{~mm}$ & $4.5 \mathrm{~mm}$ & $0 \mathrm{~mm}$ & 4.5 \\
\hline
\end{tabular}

\section{FINAL CONSIDERATIONS}

Controlling Newton's third law and the tipping and torque of anterior and posterior segments is critical to successfully closing extraction spaces. Two methods have been used for extraction space closure: (1) En-masse retraction of the incisors and canines; $;^{1,2}$ (2) A two-step retraction, beginning with the distalization of the canines and followed by incisor retraction. ${ }^{3,4}$ The first method has two types of mechanics. The first is segmented mechanics, in which the anterior teeth are retracted directly with a spring such as a T-loop space closure spring, ${ }^{3}$ which needs a complicated design to achieve bodily tooth movement. ${ }^{4}$ The second type is sliding mechanics, where incisors and canines are retracted with an archwire guided by the brackets placed on the posterior teeth. ${ }^{3,4}$ However, in sliding mechanics, friction occurs at the wire-bracket interface, dissipating some of the applied force and decreasing the rate of tooth movement. ${ }^{5-8}$ To overcome the friction, a high magnitude force has to be applied, which might be detrimental to the anchorage unit. ${ }^{9,10}$ 
To achieve controlled extraction space closure, the appliance used must deliver determinable force systems regulated by the orthodontist, and not produce closure in an indeterminate way. Only when force systems are definable, dental movements are predictable and treatment outcomes can be predicted with confidence. ${ }^{11}$ In addition, the force systems should move teeth with an optimal velocity and an extended range of activation, while producing a relatively constant force system, which will reduce the tissue injury and the number of appointments, while yielding tooth movement with a nearly constant center of rotation. This case report described a mechanical system that met these goals without using temporary anchorage devices (TADs). TADs have expanded the horizons of orthodontic treatment, because they allow treatment to proceed successfully with virtually no anchorage loss and minimal patient cooperation. However, sometimes we are faced with patients that, for different reasons, do not want invasive methods, such as TADs, and/or extraoral force for anchorage matters.

Therefore, precise control of tooth movement during closure of extraction spaces in three dimensions is of paramount importance in meeting treatment goals. This includes control of the anchorage units, vertical forces, root positions, and rotations. Many methods for controlling the posterior anchorage movement in extraction space closure have been described. ${ }^{2-5,10,11,13}$ Regulation of the space closure is ultimately determined by the biomechanical forces applied to the anterior and posterior teeth. Variation in the force and moment magnitude and the moment-to-force ratio are important determinants of the orthodontic tooth movement. Tweed tip-back bends, Begg or tip-edge mechanics, intermaxillary elastics, and headgear can produce differences in the moment-to-force ratios (and the moment differential) between the anterior teeth and posterior teeth. This difference in the moment-toforce ratio acting on the anterior versus the posterior segments is produced by either applying unequal moments (a moment differential) or unequal forces (i.e., use of a headgear or intermaxillary elastics).

The advantage of using a segmented mechanics is that it is possible to develop a precise and predictable force system between an anterior and a posterior segments, enabling sagittal, vertical and axial control of the anterior and posterior teeth. The mechanism described in this case report enables the magnitude of the moments and forces delivered to be well controlled. ${ }^{12}$ Consequently, constant levels of force can be maintained, and the moment to force ratio $(\mathrm{M} / \mathrm{F})$ at the centers of resistance is easily regulated to produce the desired tooth movements. If sliding mechanics or closing loops archwires techniques were used for retraction, the posterior dental anchorage would be significantly affected. Consequently, the treatment time would probably be longer. Furthermore, retracting the canines without prior alignment and leveling save treatment times and allows you to use the window of opportunity created by the corticotomy during the extraction of the first premolars.

To design this segmented mechanics optimally to obtain the desired force system, the position of the center of resistance of the anterior teeth may be estimated on a lateral cephalometric X-ray film. In clinical situations such as the one reported in this paper, where incisors are proclined, the center of resistance of the anterior segment lies further lingual to the incisors crowns. ${ }^{13}$ It is important to monitor the anterior and posterior segments and alter the force system if indicated, especially the axial inclination of the anterior teeth. ${ }^{14}$ The resulting force system can be modified by changing the magnitudes and points of application of the distal forces with respect to the center of resistance of the anterior segment.

Taking all together, this segmented approach is clinically advantageous because it allows simultaneous control of tooth movement in the vertical, axial and sagittal planes. The low load-deflection rate of this system delivers a constant retrusive force, and the levels of force can be maintained low. Moreover, the design of this appliance allows the orthodontist to deliver a wellcontrolled, statically determinate force system in which only minimal chairside adjustments are required. 


\section{REFERENCES}

1. McLaughlin RP, Bennett JC. The transition from standard edgewise to preadjusted appliance systems. J Clin Orthod. 1989 Mar;23(3):142-53.

2. Bennett JC, McLaughlin RP. Controlled space closure with a preadjusted appliance system. J Clin Orthod. 1990 Apr;24(4):251-60.

3. Nanda R, Kuhlberg A. Biomechanical basis of extraction space closure. In: Nand R, editor. Biomechanics in clinical orthodontics. Philadelphia: Saunders; 1997. p. 156-87.

4. Burstone CJ. The segmented arch approach to space closure. Am J Orthod. 1982 Nov; 82(5):361-78

5. Nanda R, Ghosh J. Biomechanical considerations in sliding mechanics. In: Nanda R, editor. Biomechanics in clinical orthodontics. Philadelphia: Saunders; 1997. p. 188-217.

6. Kusy RP, Whitley JQ. Prewitt MJ. Comparison of the frictional coefficients for selected archwire-bracket slot combinations in the dry and wet states. Angle Orthod. 1991 Winter;61(4):293-302.

7. Noda T, Okamoto Y, Hamanaka H. Friction property of orthodontic wires evaluation by static frictional coefficients. J Jpn Orthod Soc. 1993:52:15460.
8. Frank CA, Nikolai RJ. A comparative study of frictional resistances between orthodontic bracket and arch wire. Am J Orthod. 1980 Dec;78(6):593-609.

9. Proffit WR. Contemporary orthodontics. St Louis: Mosby; 1986

10. Kojima Y, Fukui H. Numeric simulations of en-masse space closure with sliding mechanics. Am J Orthod Dentofacial Orthop. 2010 Dec;138(6):702. e1-6; discussion 702-4.

11. Braun S, Sjursen RC Jr, Legan HL. On the management of extraction sites. Am J Orthod Dentofacial Orthop. 1997 Dec;112(6):645-55

12. Burstone $\mathrm{CJ}$, Koenig $\mathrm{HA}$. Optimizing anterior and canine retraction. Am J Orthod. 1976 July; 70(1):1-19

13. Shroff B, Lindauer SJ, Burstone CJ, Leiss JB. Segmented approach to simultaneous intrusion and space closure: biomechanics of the three-piece base arch appliance. Am J Orthod Dentofacial Orthop. 1995 Feb;107(2):13643.

14. Xu TM, Zhang X, Oh HS, Boyd RL, Korn EL, Baumrind S. Randomized clinica trial comparing control of maxillary anchorage with 2 retraction techniques. Am J Orthod Dentofacial Orthop. 2010 Nov:138(5):544.e1-9; discussion 544-5. 